\title{
Aplikasi Citra Untuk Mendeteksi dan Mengenali Warna Menggunakan Algoritma Midpoint
}

\author{
Nurlindasari Tamsir ${ }^{1}$, Suryani $^{2}$, Nirwana $^{3}$ \\ 123, Program Studi Teknik Informatika STMIK Dipanegara Makassar \\ Jl. Perintis Kemerdekaan Kemerdekaan Km.9 Makassar, Tamalanrea Makassar 90000 - Indonesia \\ e-mail: ${ }^{1}$ stmik14@gmail.com, ${ }^{2}$ a.surya.a.z@gmail.com, ${ }^{3}$ nirwana2006@dipanegara.ac.id
}

\begin{abstract}
Abstrak
Pengolahan citra berhubungan erat dengan warna, namun ada beberapa metode pada pengolahan citra yang mempunyai banyak kekurangan seperti metode HSV yang hanya dapat mengenali 6 warna saja dan beberapa model pengenalan citra lainnya yang penggunaannya tidak secara real time. Tujuan penelitian untuk merancang aplikasi pengolahan citra dalam mendeteksi warna berbasis android mobile dan mengimplementasikan algoritma Midpoint kedalam aplikasi ketika melakukan proses pengenalan citra. Dalam penelitian ini penulis membuat aplikasi berbasis android dan menggunakan algoritma Midpoint. Algoritma Midpoint merupakan algortima untuk mendapatkan titik tengah dari layar pada saat mengambil gambar objek menggunakan kamera smartphone. Titik tengah diperoleh dengan mendapatkan parameter yaitu koordinat $1 / 2$ tinggi untuk sumbu $\mathrm{y}$, dan $1 / 2$ lebar untuk sumbu $\mathrm{x}$ sehingga dapat diperoleh titik pusat dari tengah layar. Bahasa pemrograman yang digunakan adalah pemrograman Java dengan database SQLite, sedangkan alat desain menggunakan UML. Penelitian ini menggunakan metode sequential linear yaitu analisa, desain, penulisan kode program, dan pengujian. Dengan mengkombinasikan penggunaan android dan algoritma ini maka diharapkan pengguna lebih mudah dalam mengenali dan mendeteksi warna secara real time.
\end{abstract}

Kata kunci - Citra, Warna, Midpoint, Smartphone

\begin{abstract}
Image processing is closely related to color, but there are several methods in image processing that have many shortcomings such as the HSV method which can only recognize 6 colors and several other image recognition models that are not used in real time. The research objective is to design an image processing application in detecting color based on android mobile and implementing the Midpoint algorithm into the application when performing the image recognition process. In this study, the authors made an android-based application and used the Midpoint algorithm. The Midpoint Algorithm is an algorithm for getting the center point of the screen when taking pictures of objects using a smartphone camera. The center point is obtained by obtaining a parameter, namely the coordinates of $1 / 2$ the height for the $y$-axis and $1 / 2$ the width for the $x$-axis so that the center point of the screen center can be obtained. The programming language used is Java programming with SQLite database, while the design tools use UML. This study uses a linear sequential method, namely analysis, design, writing program code, and testing. By combining the use of Android and this algorithm, it is hoped that users will find it easier to recognize and detect colors in real time.
\end{abstract}

Keywords - Image, Color, Midpoint, Smartphone 


\section{PENDAHULUAN}

Pengolahan citra adalah salah satu cabang dari ilmu informatika. Pengolahan citra menjurus pada usaha untuk melakukan transformasi suatu visual / gambar menjadi visual lain dengan menggunakan teknik tertentu. Pengolahan citrabertujuan memperbaiki kualitas visualisasi gambar agar mudah diinterpretasikan oleh manusia atau mesin (dalam hal ini komputer). Pengolahan citra berhubungan erat dengan warna. Pada kebanyakan kasus, terutama untuk keperluan penampilan secara visual, nilai data digital merepresentasikan warna dari citra yang diolah. Format citra digital yang banyak dipakai adalah Citra Biner (monokrom), Citra Skala Keabuan (gray scale), Citra Warna (true color), dan Citra Warna Berindeks.

Warna adalah spektrum tertentu yang terdapat di dalam suatu cahaya sempurna (berwarna putih). Nilai warna ditentukan oleh tingkat kecerahan maupun kesuraman warna. Nilai ini dipengaruhi oleh penambahan putih ataupun hitam. Penelitian memperlihatkan bahwa kombinasi warna yang memberikan rentang paling lebar adalah red $(R)$, green $(G)$ dan blue $(B)$. Ketiga warna tersebut merupakan warna pokok yang biasa disebut RGB. Warna lain dapat diperoleh dengan mencampurkan ketiga warna pokok tersebut dengan perbandingan tertentu. Setiap warna pokok mempunyai intensitas sendiri dan selama ini proses pengolahan citra dilakukan dengan menggunakan beberapa metode salah satunya adalah metode HSV. Metode HSV mengguanakan model hue, saturation, value (HSV). Dengan menggunakan model ini, sebuah obyekdengan warna tertentu dapat dideteksi dan mengurangipengaruh intensitas cahaya dari luar dan hanya mengenali 6 warna yaitu coklat, kuning, hijau, biru, hitam dan putih. Dan beberapa model pengenalan citra lainnya digunakan untuk mengenali wajah yang penggunaanya tidak secara real time melainkan harus diolah dengan memasukkan gambar kedalam komputer desktop.

Aplikasi ini menggunakan sistem operasi android cukup dengan menggunakan aplikasi, kemudian aplikasi akan mengakses kamera dimana dari kamera ini di implementasikan algoritma mid point. Algoritma ini dapat mengenali semua warna mengingat pengenalan warnanya berdasarkan titik pixel dan berdasarkan jumlah database yang dimasukan. Algoritma ini diimplementasikan pada smartphone sehingga penggunaannya lebih mudah dan real time dibandingkan algoritma citra lainnya yang diimplementasikan pada komputer desktop.

Tujuan penelitian yaitu merancang aplikasi pengolahan citra untuk mendeteksi warna berbasis android dan mengimplementasikan algoritma mid point kedalam aplikasi ketika melakukan proses pengenalan citra.

Aplikasi adalah penggunaan dalam suatu komputer, intruksi (instruction) atau pernyataan (statement) yang disusun sedemikian rupa sehingga komputer dapat memproses input menjadi output[1]. Aplikasi Secara istilah adalah suatu program yang siap untuk digunakan yang dibuat untuk melaksanankan suatu fungsi bagi pengguna jasa aplikasi serta penggunaan aplikasi lain yang dapat digunakan oleh suatu sasaran yang akan dituju[2].

Citra merupakan istilah lain untuk gambar sebagai salah satu komponen multimedia yang memegang peranan yang sangat penting sebagai bentuk informasi visual. Citra mempunyai karakteristik yang tidak dimiliki oleh data teks, yaitu citra kaya dengan informasi. Secara harfiah, citra (image) adalah gambar pada bidang dwimatra (dua dimensi). Ditinjau dari sudut pandang matematis, citra merupakan fungsi menerus (continue) dari intensitas cahaya pada bidang dwimatra. Sumber cahaya menerangi objek, objek memantulkan kembali sebagai dari berkas cahaya tersebut.Pantulan cahaya ini ditangkap oleh alat-alat optik, misalnya mata pada manusia, kamera, pemindai (scanner), dan sebagainya. Sehingga bayangan objek yang disebut citra tersebut terekam[3]. Pengolahan citra merupakan bidang yang bersifat multidisiplin, yang terdiri dari banyak aspek, antara lain: fisika (optik, nuklir, gelombang, dll), elektronika, matematika, seni, fotografi, dan teknologi komputer. Pengolahan citra (image processing) memiliki hubungan yang sangat erat dengan disiplin ilmu yang jika sebuah disiplin ilmu dinyatakan dalam bentuk proses suatu input menjadikan output, maka pengolahan citra memiliki input berpupa citra serta output berupa citra[4]. 
Algoritma adalah prosedur komputasi yang mengambil beberapa nilai atau kumpulan nilai sebagai input kemudian di proses sebagai input sehingga algoritma merupakan urutan langkah komputasi yang mengubah input menjadi output[5]. Algoritma Midpoint untuk Penggambaran Garis Algoritma midpoint dikembangkan oleh Pitteway pada tahun 1967. Titik abu-abu menyatakan posisi piksel, titik hitam menyatakan posisi piksel yang telah digambar dengan langkah-langkah sebagai-berikut:

1. Gambar piksel pertama $(\mathrm{x} 1, \mathrm{y} 1)$.

2. Tentukan tanda variabel penentu. Jika variabel penentu bernilai positif, increment $x$ dan $y$ dan tambahkan $(\mathrm{a}+\mathrm{b})$ pada vaiabel penentu, sebaliknya increment $\mathrm{x}$ dan y dan tambahkan

(a) pada variabel penentu.

3. Plot piksel pada posisi $(x, y)$.

4. Ulangi langkah mulai langkah kedua, sampai piksel terakhir (x2,y2).[6].

Warna merupakan komponen yang sangat utama dan umum dipergunakan untuk memperindah suatu karya seni, utamanya lukisan. Pelajaran mengenal warna dimulai saat anak belajar untuk melukis atau menggambar, karena dengan belajar menggambar anak secara tidak sadar telah diajak untuk belajar mengenal warna. Hasil pembelajaran mengenal warna kemudian tidak hanya berguna untuk hal-hal demikian, namun sangat membantu seseorang di kelak kemudian hari untuk mengenal berbagai macam aturan yang disimbolkan dengan warna. Contoh penggunaan simbol warna untuk aturan adalah pada peraturan rambu-rambu lalu lintas di jalan raya yang berlaku sama di seluruh tempat di dunia ini[7].

\section{METODE PENELITIAN}

Pengumpulan data pada penelitian ini melalui data primer yaitu data yang diperoleh atau dikumpulkan dari beberapa sumber. Pengumpulan data primer ini menggunakan metode studi lapangan yaitu: observasi, melakukan pengamatan secara langsung terhadap orang yang sulit mengenali warna dan hasil solusi yang akan diimplementasikan serta data sekunder yaitu buku dari perpustakaan, buku terkait penelitian, serta literature online yang diperlukan dalam pembuatan aplikasi.

Dalam mengembangkan sistem informasi diperlukan suatu metode pengembangan sistem salah satunya metode sequential linear. Adapun tahap yang ada pada metode sequential linear, sebagai berikut: analisa, desain, penulisan kode program, pengujian.

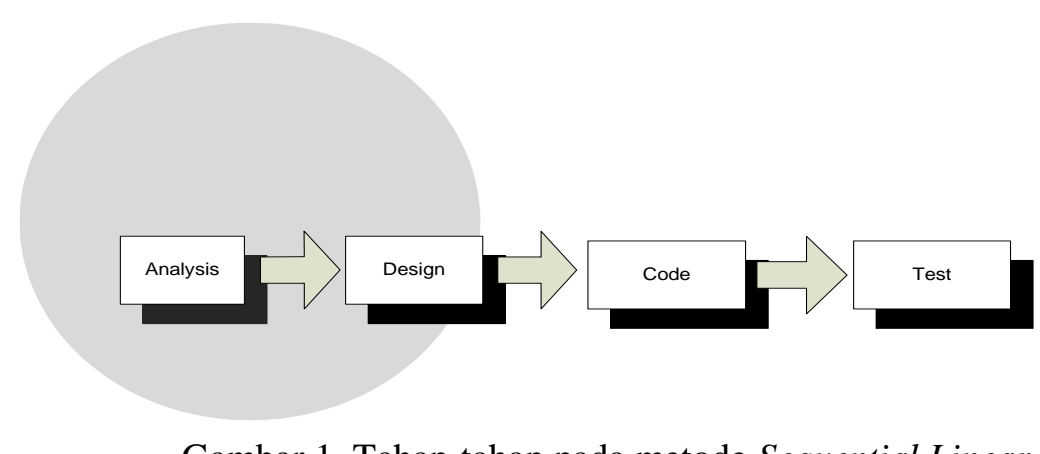

Gambar 1. Tahap-tahap pada metode Sequential Linear

Perangkat keras yang digunakan terdiri dari serangkai komputer (hardware), serta Smartphone OS Android 5.0 Lollipop, sedangkan perangkat lunak terdiri atas Bahasa Pemrograman Java dengan menggunnakan database SQLite, Android Studio. Alat desain sistem, yang terdiri atas Use case, Class diagram, Activity diagram. 


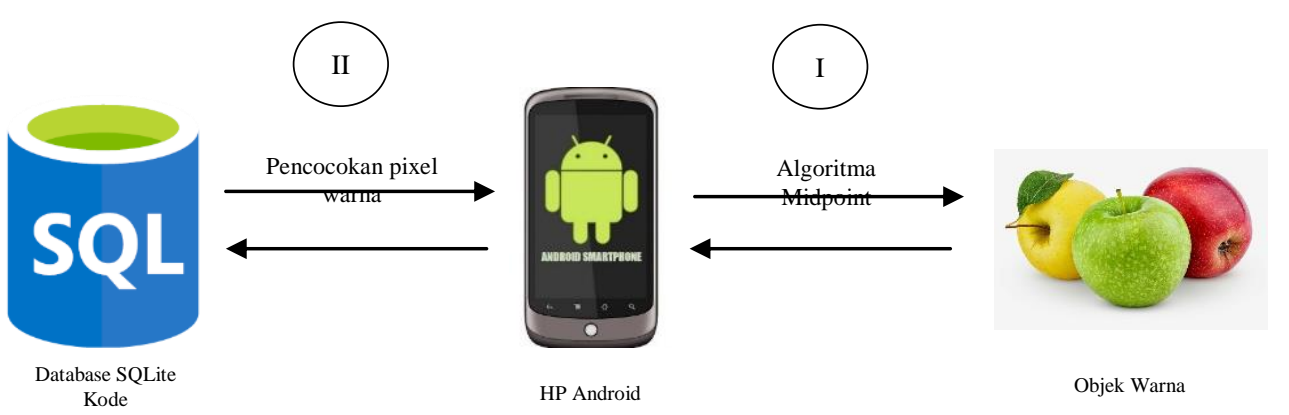

Gambar 2. Arsitektur Teknologi

Pertama, android akan mengenali object warna menggunakan algoritma mid point kemudian akan memproses ke database sqlite kode warna dengan mencocokkan pixel warna yang akan dikenali.

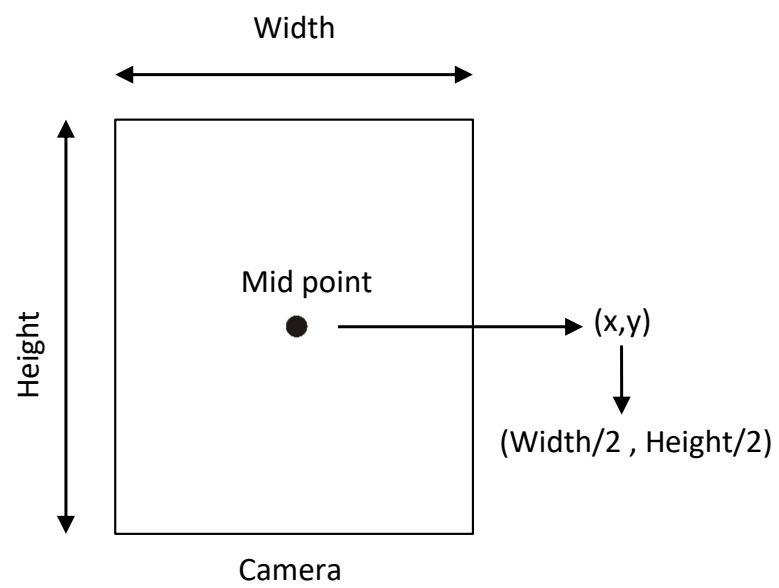

Gambar 3. Algoritma Mid Point

Algoritma mid point yaitu algortima untuk mendapatkan titik tengah dari layar pada saat mengambil gambar object menggunakan camera smartphone. Titik tengah diperoleh dengan mendapatkan hasil koordinat $1 / 2$ tinggi untuk sumbu $y$, dan $1 / 2$ lebar untuk sumbu $\mathrm{x}$ sehingga dapat diperoleh titik pusat dari tengah layar.

\section{HASIL DAN PEMBAHASAN}

Aplikasi ini berbasis android dimana membantu untuk mengenali warna dengan mengimlementasikan algoritma mid point. Aplikasi ini akan berjalan ketika dibuka kemudian dilanjutkan dengan menampilkan interface camera untuk mengambil gambar kemudian saat titik tengah ditekan maka aplikasi akan menampilkan nama warna serta suara yang membacakan nama warna tersebut. Dalam pembuatan aplikasi ini ada beberapa komponen utama yaitu adalah : Camera, aplikasi dapat berjalan hanya dengan menggunakan perangkat dari smartphone dalam hal ini adalah perangkat yang ada dalam smartphone. Semakin tinggi pixel camera maka akan semakin baik dalam mengenali warna. SQLite adalah database yang digunakan untuk menyimpan nama warna, kode hexa, yang nantinya akan ditampilkan dalam aplikasi. JAVA, merupakan bahasa yang digunakan untuk aplikasi berbasis mobile dimana aplikasi akan yang menarik data dari database berdasarkan hasil pengenalan dari algoritma mid point dari camera smartphone. 


\section{$3.1 U M L$}

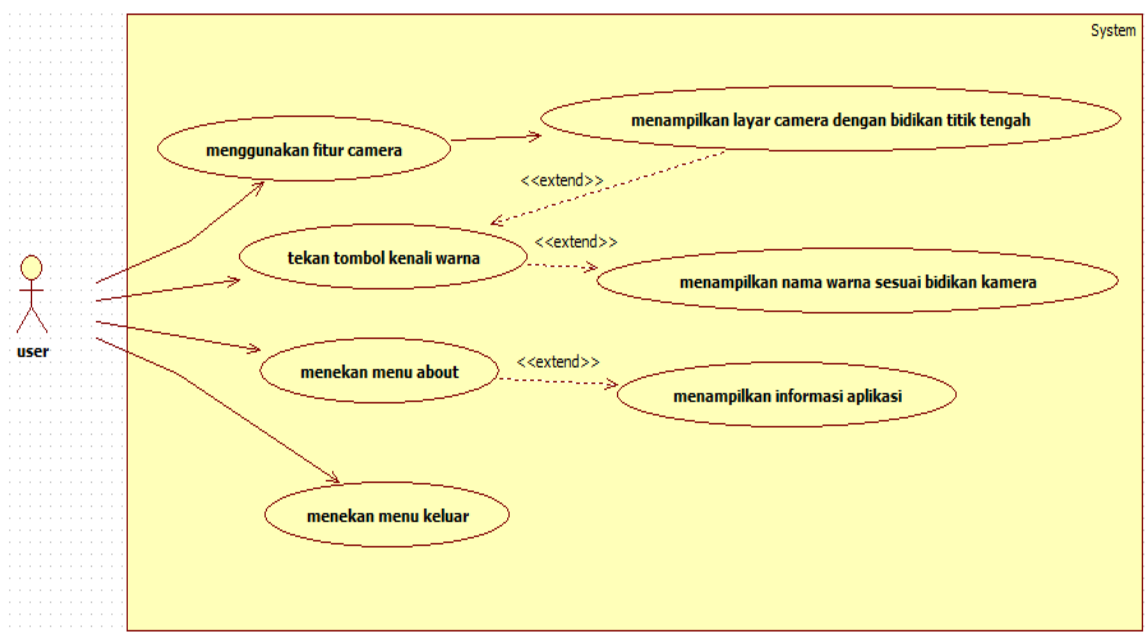

Gambar 4. Use Case Diagram Aplikasi

Berdasarkan gambar diatas terdapat hanya ada 1 aktor yaitu user pengguna yang menggunakan aplikasi cukup membuka aplikasi maka akan diarahkan langsung menggunakan kamera untuk mulai mengenali warna. Dari aplikasi akan menarik data berdasarkan database yang ada pada perangkat yang di install aplikasi tersebut.

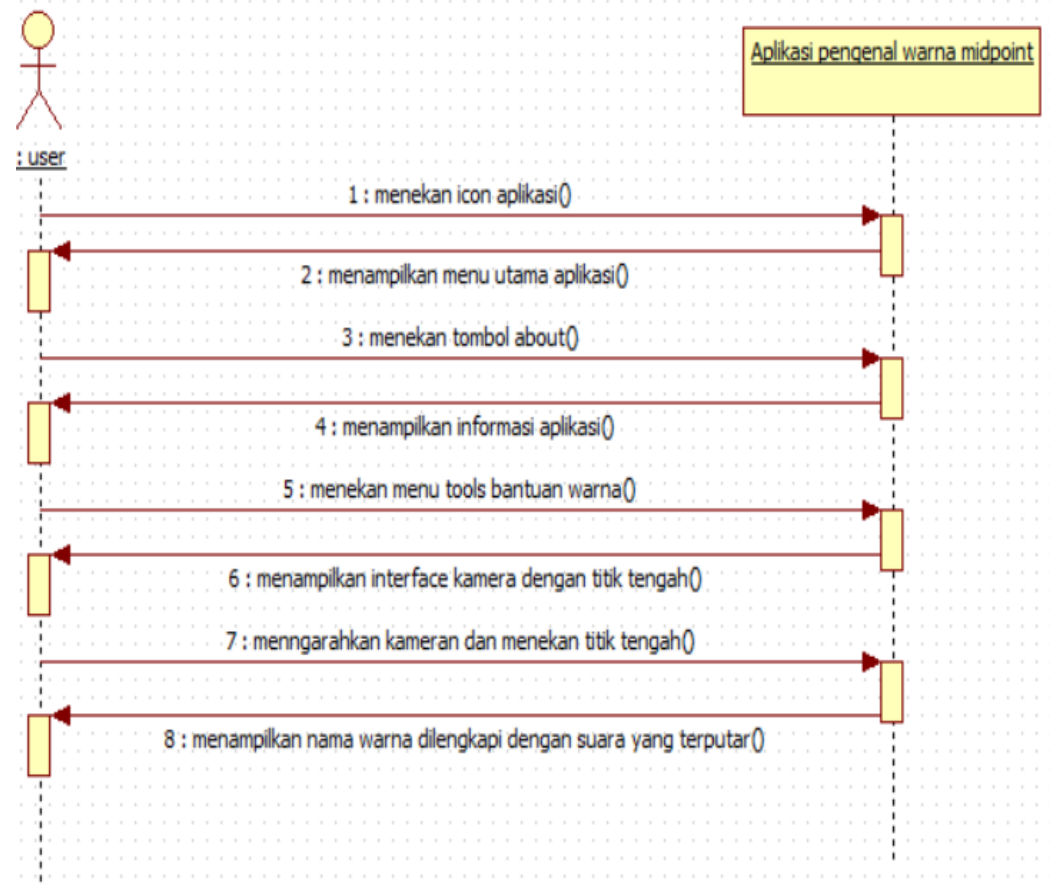

Gambar 5. Sequence Diagram Sistem

Sequence diagram ini akan memperlihatkan interaksi dari setiap actor dengan sistem aplikasi yang dibuat dalam hal gambaran diatas terlihat bahwa ketika aplikasi di jalankan, maka aplikasi akan menampilkan menu yang terdiri dari dua menu yaitu menu about yang akan memberikan informasi mengenai informasi aplikasi, dan menu alat bantu warna guna untuk mulai proses pengenalan warna. Algoritma mid point akan jalan ketika aplikasi ditekan melalui menu alat bantu warna. Algoritma mid point akan mengambil nilai pixel untuk sebagai proses pengenalan nama warna. 


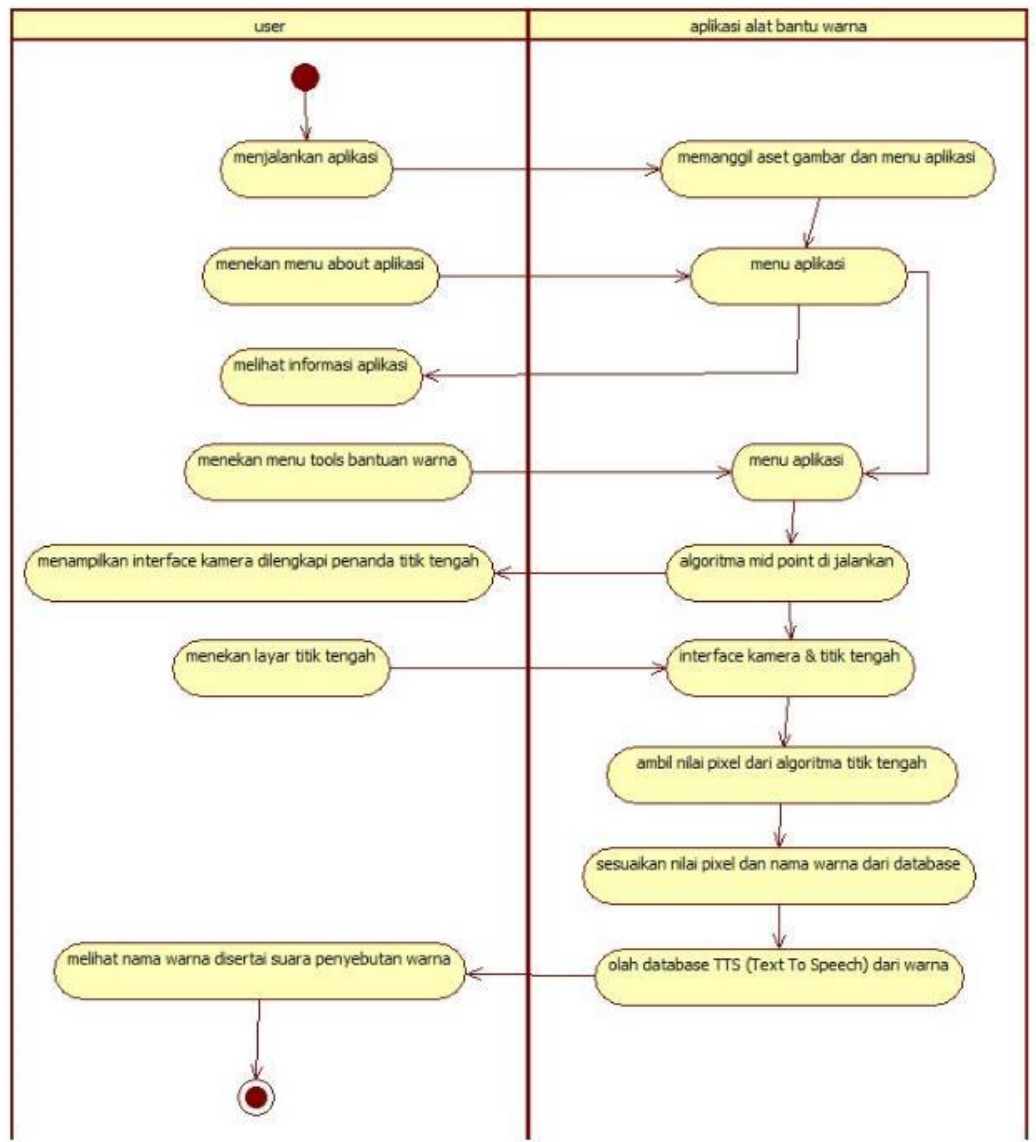

Gambar 6. Activity Diagram Sistem

\subsection{Tampilan Aplikasi}

Icon aplikasi menggunakan warna umum dari aplikasi yang berwarna hijau yang menjadi penanda jika aplikasi terinstal dalam smartphone android.
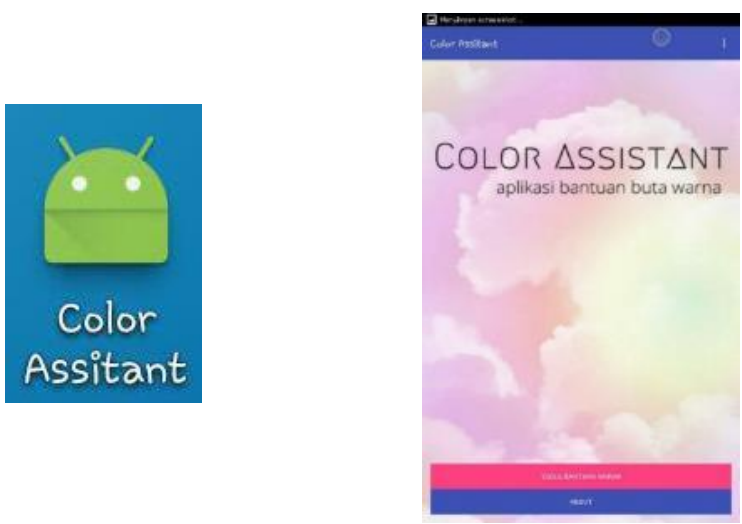

Gambar 7. Icon Aplikasi Android

Pada Gambar 7, menampilkan ketika icon aplikasi ditekan maka interface awal aplikasi akan muncul. 


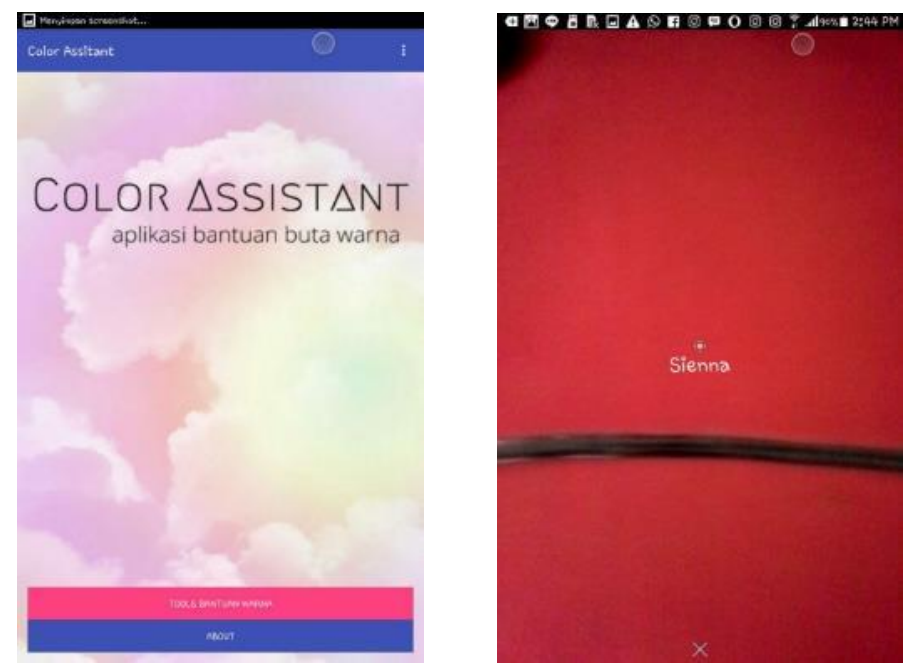

Gambar 8. Menu Tools Bantu warna

Pada Gambar 8, terlihat ketika menu tools bantu warna ditekan maka aplikasi akan menampilkan interface kamera disertai dengan titik tengah hasil dari algoritma mid point.
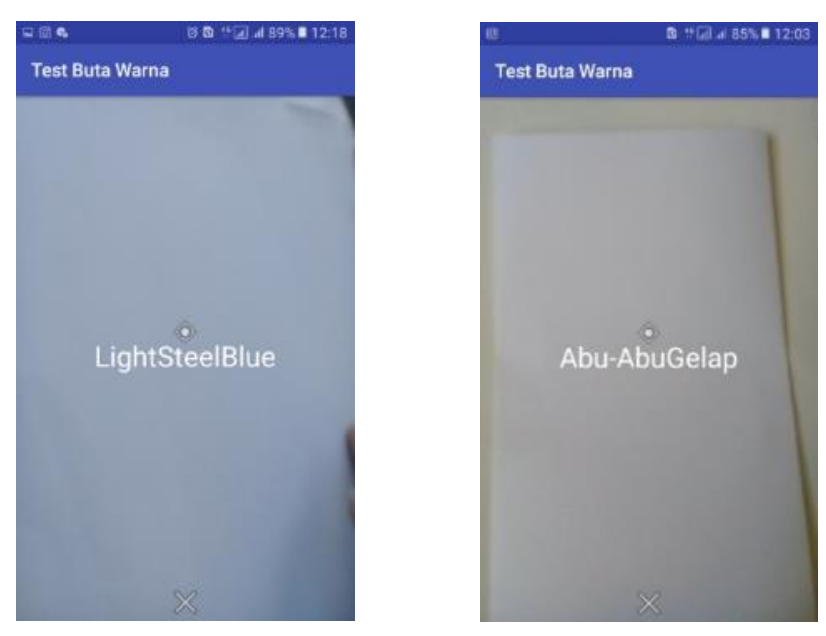

Gambar 9, Input arah pointing ke objek putih

Pada Gambar 9, dilakukan test warna dengan mengarahkan titik tengah pointing kearah objek dan menekan layar. Hasil dari Objek putih menampilkan nama warna (Light Steel Blue) dikarenakan intensitas cahaya yang ada diluar ruangan menyebabkan objek putih terpantul dengan cahaya matahari. Sedangkan hasil dari Objek putih menampilkan nama warna (Abu-Abu Gelap). Hal ini dikarenakan faktor intensitas cahaya yang ada didalam ruangan agak gelap, sehingga mempengaruhi sensor pendeteksian warna. 


\subsection{Pengujian}

Berdasarkan teknik pengujian BlackBox yang telah dilakukan maka secara umum hasil pengujian aplikasi menunjukkan tidak terdapatnya kesalahan (valid) pada fungsionalitas dari aplikasi dengan menguji semua modul.

Tabel 1. Pengujian BlackBox

\begin{tabular}{|c|c|c|c|c|}
\hline No & Skenario Pengujian & Hasil yang diharapkan & $\begin{array}{c}\text { Hasil } \\
\text { Pengujian }\end{array}$ & Kesimpulan \\
\hline 1 & $\begin{array}{l}\text { Menekan icon } \\
\text { aplikasi }\end{array}$ & $\begin{array}{l}\text { Sistem akan berhasil } \\
\text { Menampilkan interface } \\
\text { awal aplikasi }\end{array}$ & $\begin{array}{l}\text { Sesuai } \\
\text { Harapan }\end{array}$ & Valid \\
\hline 2 & $\begin{array}{l}\text { Menekan menu } \\
\text { about }\end{array}$ & $\begin{array}{l}\text { Sistem akan berhasil } \\
\text { Menampilkan info } \\
\text { aplikasi }\end{array}$ & $\begin{array}{l}\text { Sesuai } \\
\text { Harapan }\end{array}$ & Valid \\
\hline 3 & $\begin{array}{l}\text { Menekan menu tools } \\
\text { bantu warna aplikasi }\end{array}$ & $\begin{array}{l}\text { Sistem akan berhasil } \\
\text { Menampilkan interface } \\
\text { kamera dilengkapi titik } \\
\text { point tengah aplikasi }\end{array}$ & $\begin{array}{l}\text { Sesuai } \\
\text { Harapan }\end{array}$ & Valid \\
\hline 4 & $\begin{array}{l}\text { Mengarahkan point } \\
\text { titik tengah ke objek } \\
\text { warna putih } \\
\text { menggunakan } \\
\text { kamera HP 8MP dan } \\
\text { 13MP }\end{array}$ & $\begin{array}{l}\text { Sistem kurang tepat } \\
\text { menampilkan nama } \\
\text { warna yang menghampiri } \\
\text { ke objek putih karena } \\
\text { efek dari intensitas } \\
\text { cahaya yang masuk } \\
\text { sehingga pendeteksian } \\
\text { warna lebih ke Abu- } \\
\text { Abuan }\end{array}$ & $\begin{array}{l}\text { Tidak } \\
\text { Sesuai } \\
\text { Harapan }\end{array}$ & Tidak Valid \\
\hline 5 & $\begin{array}{l}\text { Mengarahkan point } \\
\text { titik tengah ke objek } \\
\text { warna merah } \\
\text { menggunakan } \\
\text { kamera HP 8MP dan } \\
\text { 13MP }\end{array}$ & $\begin{array}{l}\text { Sistem Berhasil } \\
\text { Menampilkan nama } \\
\text { warna dari merah yaitu } \\
\text { Sienna (merah } \\
\text { kecoklatan), indian Red } \\
\text { (merah kehitaman), } \\
\text { Salmon (merah kemerah } \\
\text { mudaan). }\end{array}$ & $\begin{array}{l}\text { Sesuai } \\
\text { Harapan }\end{array}$ & Valid \\
\hline 6 & $\begin{array}{l}\text { Mengarahkan point } \\
\text { titik tengah ke objek } \\
\text { warna biru } \\
\text { menggunakan } \\
\text { kamera HP 8MP dan } \\
\text { 13MP }\end{array}$ & $\begin{array}{l}\text { Sistem Berhasil } \\
\text { Menampilkan nama } \\
\text { warna dari biru yaitu } \\
\text { Royal Blue, Biru } \\
\text { Dongker, Midnight Blue } \\
\text { (Biru Gelap) dan Steel } \\
\text { Blue. }\end{array}$ & $\begin{array}{l}\text { Sesuai } \\
\text { Harapan }\end{array}$ & Valid \\
\hline
\end{tabular}




\section{KESIMPULAN}

Kesimpulan yang dapat ditarik dari uraian di atas sebagai berikut:

1. Algoritma Mid Point bekerja dengan baik dalam pengenalan warna yakni dengan mengambil nilai pixel kemudian akan diterjemahkan kedalam nama warna sesuai dengan database yang tersimpan.

2. Aplikasi dapat memutar suara dengan memanfaatkan database suara yang ada pada smartphone ketika nama warna telah ditemukan.

3. Modul yang telah dibuat pada android telah berjalan sesuai dengan harapan menggunakan pengujian sistem Black Box.

\section{SARAN}

Saran untuk penelitian selanjutnya adalah:

1 Mengembangkan aplikasi dengan sistem operasi lain seperti windows phone, iphone.

2 Menggunakan kamera dengan resolusi tinggi dalam proses pengenalan warna agar kualitas pengenalan warna dapat lebih baik lagi.

\section{UCAPAN TERIMA KASIH}

Penulis mengucapkan terima kasih kepada semua pihak yang telah memberi dukungan baik materil maupun finansial terhadap penelitian ini.

\section{DAFTAR PUSTAKA}

[1] A. Budiman, A. Mulyani, and Sekolah Tinggi Teknologi Garut, "Rancang Bangun Aplikasi Sistem Informasi Persedian Barang di TB. Indah Jaya Berbasis Desktop," Algoritma, vol. 13, no. 2, pp. 374-378, 2017.

[2] F. Fansuri, "Pembangunan Aplikasi Child Tracker Berbasis Assisted - Global Positioning System (A-GPS) Dengan Platform Android," Jurnal Ilmiah Komputer dan Informatika (KOMPUTA), vol. 1, no. 1, pp. 1-8, 2015.

[3] P. T. K. Putra and N. K. A. Wirdiani, "Pengolahan Citra Digital Deteksi Tepi Untuk Membandingkan Metode Sobel, Robert dan Canny," MERPATI, vol. 2, no. 2, p. 9, 2014.

[4] M. S. Kara, F. Wara, and M. F. Rumba, "Identifikasi Jenis Bunga Menggunakan Ekstraksi Ciri Orde Satu," Jurnal In Create (Inovasi dan Kreasi dalam Teknologi Informasi), vol. 6, pp. 22-28, 2019.

[5] A. A. T. Susilo, L. Sunardi, and Y. Waruwu, "Penerapan Algoritma Apriori Pada Data Penjualan Kosmetik di Toko Sharly Kota Lubuklinggau," Jurnal Teknik Informatika Musirawas, vol. 4, no. 2, pp. 92-100, 2019.

[6] A. Prastyo and T. M. S. Mulyana, "Aplikasi Pola Batik Menggunakan Metode Fraktal Dan Algoritma Lingkaran 8 Way Simetris," Jurnal Teknologi Informasi, vol. 10, no. 2, pp. 1-9, 2014.

[7] Y. Yudha, D. Ardhiyanta, and L. Haris, “Aplikasi Pengenalan Citra Warna Dasar," Jurnal Ilmiah Widya Teknik, vol. 15, no. 1, pp. 54-57, 2016. 